\title{
Empirical Estimation of the Width of Highway Roadside Clear Zone
}

\author{
Guozhu Cheng ${ }^{1 *}$, Xuanling Liu ${ }^{1}$, Liang $\mathrm{Xu}^{2}$, Lianzhen Wang ${ }^{1}$ \\ ${ }^{1}$ School of Traffic and Transportation, Northeast Forestry University, Harbin 150040, China \\ ${ }^{2}$ School of Civil Engineering, Changchun Institute of Technology, Changchun 130012, China
}

Corresponding Author Email: guozhucheng@nefu.edu.cn

https://doi.org/10.18280/ijsse.100212

Received: 9 April 2019

Accepted: 20 November 2019

\section{Keywords:}

roadside safety, width of clear zone, calculation method, suggestion values

\begin{abstract}
In order to provide theoretical gist and support, this paper studied calculation method of roadside clear zone's width. Firstly, main influencing factors of highway roadside clear zone's width are analyzed, including shoulder width, degree of side slope, braking reaction time, state of vehicle running on roadside (departure angle and speed). Calculation method is proposed based on classical physics theory, and the accuracy of the method is verified by the simulation test of PC-Crash software. Lastly, suggestion values of roadside clear zone's width are given. The results of this paper are expected to provide design and decision-making reference for highway designers and managers, and provide theoretical support for highway design standards and specifications, as well as revision for safety evaluation guidelines of safety evaluation guidelines.
\end{abstract}

\section{INTRODUCTION}

By the end of 2016, the total mileage of highways in China has reached 4.6963 million kilometers, while roadside accidents cover $1 / 2$ of the total number, however data from Beijing and Guizhou show that in all these accidents, the roadside accidents account for $1 / 4$ of all, resulting in a 40 percent mortality rate and more than 50 percent of serious injuries.

According to the tolerant design concept, the fault of drivers should not be at the expense of life. The roadside safety design should provide the driver who has left the lane with the ability to regain control of the vehicle and safely drive back into the lane (roadside clear zone), as shown in Figure 1. Even though it is unable to drive back into the lane, it will also make some faults resolved in the road system and finally it will be at some extent to minimize the severity of roadside accidents.

In terms of roadside clear zone design, AASHTO (American Association of State Highway and Transportation Officials) proposed in the "roadside safety design guide" that a clear zone of $9 \mathrm{~m}$ or more beyond the edge of the highway lane can be used to recover $80 \%$ of out of control vehicles; At the same time, it gave the recommended value of the clear zone on the roadside of the straight section and the correction coefficient of the horizontal curve section. The selection basis of the recommended value of the net roadside clear zone of the straight-line section includes: design speed, AADT (Annual Average Daily Traffic), slope form (fill or excavation), slope gradient [1].

In 2004, the road design manual of the Department of transportation of Montana in the United States also provided similar standards for the clear width of the roadside, and modified the recommended value of the clear width of the roadside according to the slope rate [2]. Studies in Australia have shown that the width of the safety clear zone more than $2 \mathrm{~m}$ outside the outer edge of the carriageway can significantly reduce the severity of roadside accidents [3]. The "Safety Assessment Guidelines for Highway Projects" (JTG B05-2015) [4] and studies of Hradil [5] and other scholars have given a graphic method for the width of the clear zone of the side safety of fill subgrade and excavation subgrade. The selection basis of straight-line section includes: running speed, unidirectional AADT; The curve section needs to select the correction coefficient according to the horizontal curve radius and running speed, however, the above regulations only refer to foreign research results and do not provide theoretical basis. Fan [6] analyzed the main influencing factors of the roadside width of clear zone, and built a calculation model, and gave the value of the roadside width clear zone, but its basic assumption is that the slope is flat, which is inconsistent with the actual situation.

In summary, the research results of foreign countries on the roadside width of clear zone have fully developed, the United States has incorporated it into the guidelines, and domestic research on the roadside net area mainly focus on the reference stage, furthermore, the existing regulations and researches results are insufficient in theoretical supporting. There is little consideration on design for highway road mainly limited by two factors, on one hand, the resources including money and land are needed, and on the other hand, there is little evidence. Therefore, it is really necessary to call for further considerations, studies and theoretical researches.

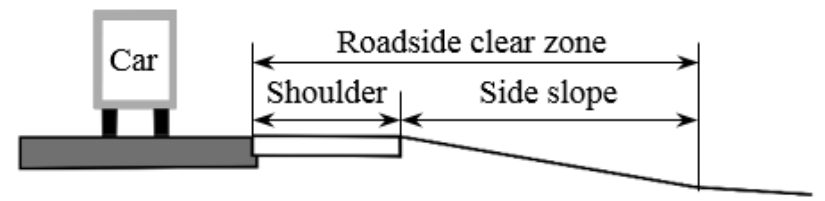

Figure 1. Roadside clear zone 


\section{CALCULATION OF PARAMETER SETTING OF WIDTH OF CLEAR ZONE}

When the vehicle rushes out of the road, in most cases, the driver will take emergency braking measures. The driving process of the vehicle can be approximated as the combination of constant speed and uniform deceleration in classical physics. The vehicle decelerates from the lane and then decelerates to a safe speed limit. The distance required depends on the combined effects of multiple factors, such as driver response time, shoulder width, slope, adhesion coefficient, safety limit speed, braking deceleration, vehicle departure speed and angle.

It is assumed that the car drives into the roadside with the angle $\beta$ deviating from the direction of travel and rushes into the slope with the slope angle $\alpha$.The angle between the travel direction of the misguided vehicle on the slope surface and the gravity direction is (90- $\theta)$, then the relations of $\alpha, \beta$ and $\theta$ are as follows:

$$
\sin (\theta)=\sin (\alpha) * \sin (\beta)
$$

\subsection{Width of right-side road shoulder}

The road shoulder is a belt-shaped structure with a certain width, which is located on the outside of the lane and can be temporarily parked by a faulty vehicle or other accident vehicle. It generally includes two parts: a hard shoulder and an earth road shoulder. The sufficient width and flat shoulder can increase the possibility of the vehicle returning safely to the driving route. At the same time, it can give the driver an open and safe feeling, which helps increase the comfort of the vehicle and avoids driving tension. It is very important for traffic safety.

"Highway Engineering Technical Standards" (JTG B012014) has clearly defined shoulder width values, high speed and Class I highways with design speeds of $60 \mathrm{~km} / \mathrm{h}$ and above, and hard shoulders and earth shoulder widths generally between $2.5 \sim 3.5 \mathrm{~m}$, between $0.5 \sim 0.75 \mathrm{~m}$ respectively.

\subsection{Angle of side slope}

The roadside clear zone is usually composed of road shoulders and moderate slopes. Most of the zone is provided by mitigation of slopes. Therefore, the slope is undoubtedly the main consideration for the design of the roadside clear zone area. There are three types of slopes: embankment, road cutting, and half-filling and half-digging (as shown in Figure 2), comparing to road cutting, embankment slopes are more prone to serious roadside accidents such as rollovers and car crashes. Therefore, this paper mainly studies embankment slopes.

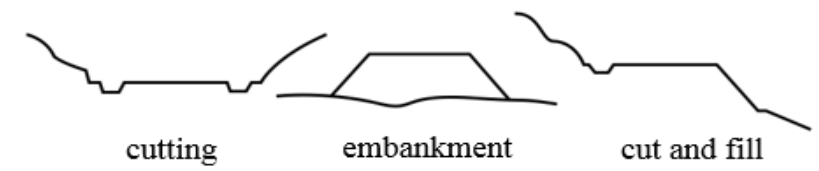

Figure 2. Cross sectional form

The Guidelines for the Safety Evaluation of Highway Projects (JTG B05-2015) [4] consider the embankment slope to be steeper than 1:3.5, and cannot be used as an effective safety net; When the slope of fill slope is between 1:3.5 and
1:5.5, a 1/2 wide slope can be used as a safe and clean area; when the slope of fill slope is 1:6 or slower, the whole slope width can be used as a safety clear zone.

\subsection{Time of braking reaction}

The braking reaction time includes the time when the driver begins to recognize danger until drivers decides on emergency braking and when he starts moving his right foot to depress the brake pedal. Relevant literature $[7,8]$ examined the selection response time of 76 drivers. The test showed that most drivers had a response time of less than $0.5 \mathrm{~s}$, and $95 \%$ of the drivers had a reaction time of less than $1.0 \mathrm{~s}$ (as shown in Figure 3). When the driver confirms the crisis, the time to move his right foot to the brake pedal is approximately 0.2 seconds, and the time for depressing the brake pedal until the vehicle brake acts is approximately $0.1 \mathrm{~s}$, then the braking response time fluctuates approximately $0.8 \mathrm{~s} \sim 1.3 \mathrm{~s}$.

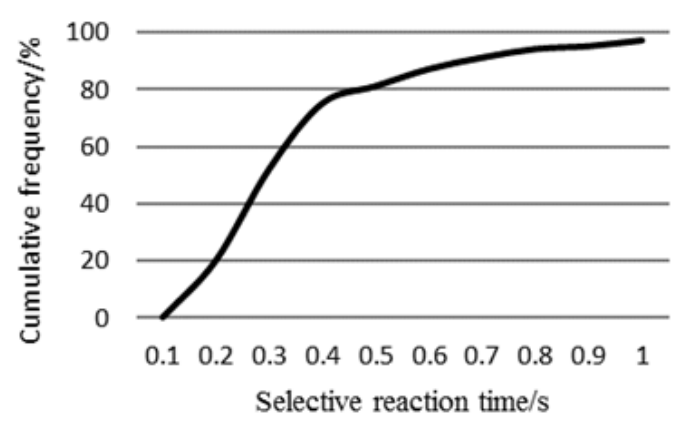

Figure 3. Drivers' selective reaction time

\subsection{Speed of safety restriction}

In fact, if the scope of the land area to be used is substantially increased according to the width of roadside net area, under the current situation of scarcity of land resources in China, it is obvious that it is difficult to achieve roadside clear zone for all roads, so it is necessary to make a reasonable choice. Restricting the speed can not only reduce the accident severity of drivers and passengers, but also rationally use roadside land resources and save engineering costs.

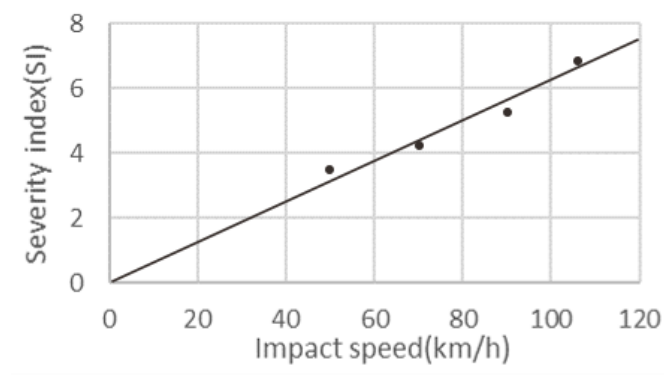

Figure 4. Relationship between impact speed and severity index in traffic accidents

Researches at home and abroad show that with the increase of vehicle speed, the possibility of vehicles rushing out of the road will increase, and in varying degrees, the severity of roadside accidents will also be exacerbated. In the US "RASP (Roadside Safety Analysis Program)" plan, it is considered that the collision speed in a traffic accident is proportional to the severity of the accident, as shown in Figure 4. At the same 
time, when the vehicle speed is greater than $40 \mathrm{~km} / \mathrm{h}$ in a traffic accident, the probability of a fatal accident increases drastically. When the vehicle speed is less than $40 \mathrm{~km} / \mathrm{h}$, the severity of the accident would be lower. Therefore, this article selects the speed of $40 \mathrm{~km} / \mathrm{h}$ as safety restriction.

\subsection{Braking deceleration}

Suppose that the gravity of the vehicle is $G$, When the vehicle enters the road side, the road shoulder is first encountered. The calculation of vehicle braking deceleration is shown in formula (2); When the vehicle is running on the side slope, the force perpendicular to the slope of the vehicle is $\operatorname{Gcos}(\alpha)$, The force parallel to the slope of a vehicle is $\operatorname{Gsin}(\alpha)$, Dividing force is $\operatorname{Gsin}(\alpha)$, The force in the direction of the vehicle is $\operatorname{Gsin}(\alpha) \sin (\beta)$, As shown in Figure 5 , it is based on the principle of dynamics:

$$
\begin{gathered}
\mu_{0} G=m a_{0} \\
F_{x 1}+F_{x 2}=\mu G \cos (\alpha) \\
\mu_{1} G \cos (\alpha)-G \sin (\alpha) \sin (\beta)=m a_{1}
\end{gathered}
$$

- $\quad \mu_{0}, \mu_{l}$ is the adhesion coefficient of the road shoulder and slope surface respectively.

- $a_{0}, a_{1}$ is the braking deceleration of the vehicle on the shoulder and slope surface respectively.

- $F_{x 1}, F_{x 2}$ is the resistance of the vehicle in the direction of the slope.

The numerical value of road adhesion coefficient is mainly related to road material and pavement condition. The adhesion coefficient of vehicles on different roads is as shown in Table $1[9]$.

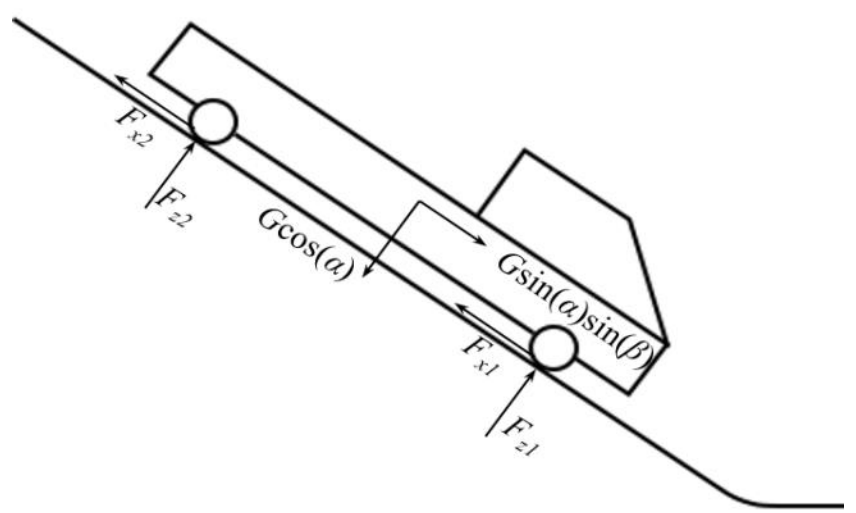

Figure 5. Force analysis of vehicle on the slope

Table 1. Adhesion coefficient of different road types

\begin{tabular}{ccc}
\hline Pavement type & State change & $\begin{array}{c}\text { Adhesion } \\
\text { coefficient }\end{array}$ \\
\hline Lawn & Dry to wet & $0.55 \sim 0.25$ \\
Asphalt and concrete pavement & Dry to wet & $0.95 \sim 0.55$ \\
sand & Dry to wet & $0.45 \sim 0.50$ \\
General soil and clay & Dry to wet & $0.55 \sim 0.40$ \\
Fertile soil and clay & Dry to wet & $0.55 \sim 0.30$ \\
Tillage soil & Dry to wet & $0.40 \sim 0.30$ \\
Pebble & Sturdy to loose & $0.35 \sim 0.30$ \\
\hline
\end{tabular}

The hard road shoulder is mainly paved by asphalt and chaotic soil pavement, generally the adhesion coefficient is 0.7 . The soil shoulder is generally paved by sandy soil or general soil, the adhesion coefficient is 0.55 . Most slope surfaces are paved by soil planting forms. Water content will affect the soil strength, and then change the adhesion coefficient, and it is advisable to 0.55 under dry roads conditions.

\subsection{Departure angle and departure speed}

Many factors determine the speed and angle of the vehicle's departure. If the driver's operation is not taken into account, the vehicle will not turn suddenly, and the vehicle's departure angle will be stable [10]. It is assumed that the motion is determined only by the steering system of the vehicle. The relationship between the departure speed and departure angle of the vehicle are as shown in Figure 6. The departure angle of the vehicle decreases with the increase of the departure speed, when the speed is infinitely great, the vehicle cannot be steered again; The smaller the speed, the greater the angle of the vehicle when the driver is driving away from the lane. However, most drivers turn suddenly when they recognize the danger, so in fact, the departure angle of theory is different from that of practice. Since there is no relevant survey data on the speed and angle of vehicle departure lane at present, according to the statistical data of the road side accident in the European "RISER (Roadside Infrastructure for Safer European Roads)" plan, the relationship between the departure speed and the departure angle in the actual road side accidents is as shown in Figure 7. 47 sample data were considered in the regression analysis. The diagram shows that the actual departure angle of the vehicle at the same speed is about $1 / 2$ of theoretical value.

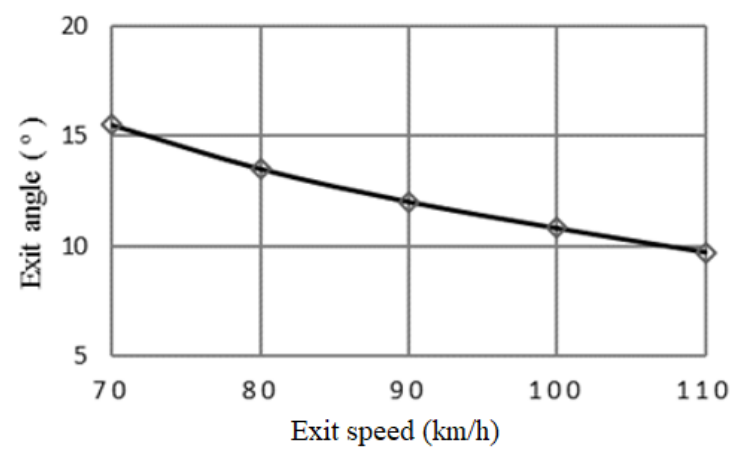

Figure 6. Theoretical relationship between departure speed and departure angle

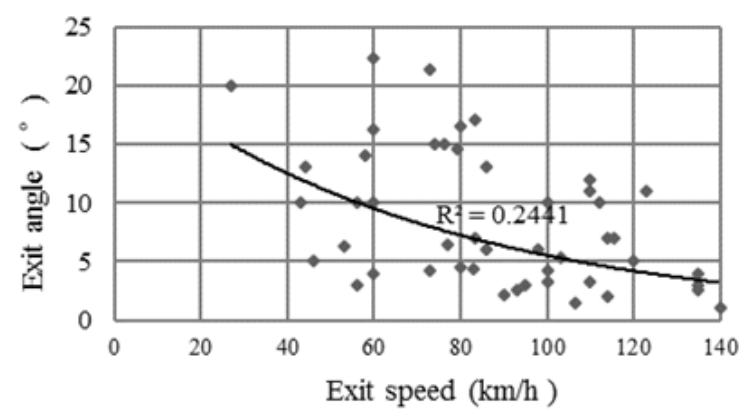

Figure 7. Actual relationship between departure angle and departure speed 


\section{CALCULATION METHOD OF THE CLEAR ZONE WIDTH}

The basic assumptions are as follows:

(1) There is sufficient width of roadside to slow down and no obstacle inside of the clear zone.

(2) The vehicle movement orbits are straight, and the direction of the vehicle is always stable and invariant in highway roadside clear zone.

The following calculation method of the width of highway roadside clear zone is proposed based on the assumptions above, the calculation process is as shown in Figure 8.

By the calculation method above, the theoretical calculation value of width of highway roadside clear zone is obtained, as shown in Table 2. Among them, the width of the shoulder $l_{0}=3 \mathrm{~m}$, slope angle $\alpha=9.46$ (side slope gradient: $1: 6$ ), braking deceleration $a_{0}=6.86 \mathrm{~m}^{2} / \mathrm{s}$, departure angle $\beta \in\left(5^{\circ} \sim 15^{\circ}\right)$, departure speed $v_{0}=(50 \sim 120) \mathrm{km} / \mathrm{h}$, braking reaction time $t_{0}=(0.8 \sim 1.3) \mathrm{s}$, speed of safety restriction $v_{\mathrm{s}}=40 \mathrm{~km} / \mathrm{h}$.

As shown in Figure 6 7, the speed of the vehicle leaving the road has a certain inverse relationship with the angle. When the departure speed is $120 \mathrm{~km} / \mathrm{h}$, the departure angle is about $5^{\circ}$; when the exit speed is $50 \mathrm{~km} / \mathrm{h}$, the exit angle is about $11^{\circ}$. As shown in Figure 2, when the exit speed is $120 \mathrm{~km} / \mathrm{h}$, the width of clear zone is $10.15 \sim 12.42 \mathrm{~m}$; when the exit speed is $50 \mathrm{~km} / \mathrm{h}$, the clear zone width range is $3.09 \sim 4.59 \mathrm{~m}$.

The upper and lower limits of the theoretical width of clear zone are calculated values corresponding to $0.8 \mathrm{~s}$ and $1.3 \mathrm{~s}$ respectively. The road designers should firstly consider the upper limit of theoretical width, which is very important to improve the safety level of the road side, and the basic braking reaction time of the driver is $0.8 \mathrm{~s}$. Therefore, the setting of roadside clear zone should at least meet the requirements of the lower limit of theoretical clear width.

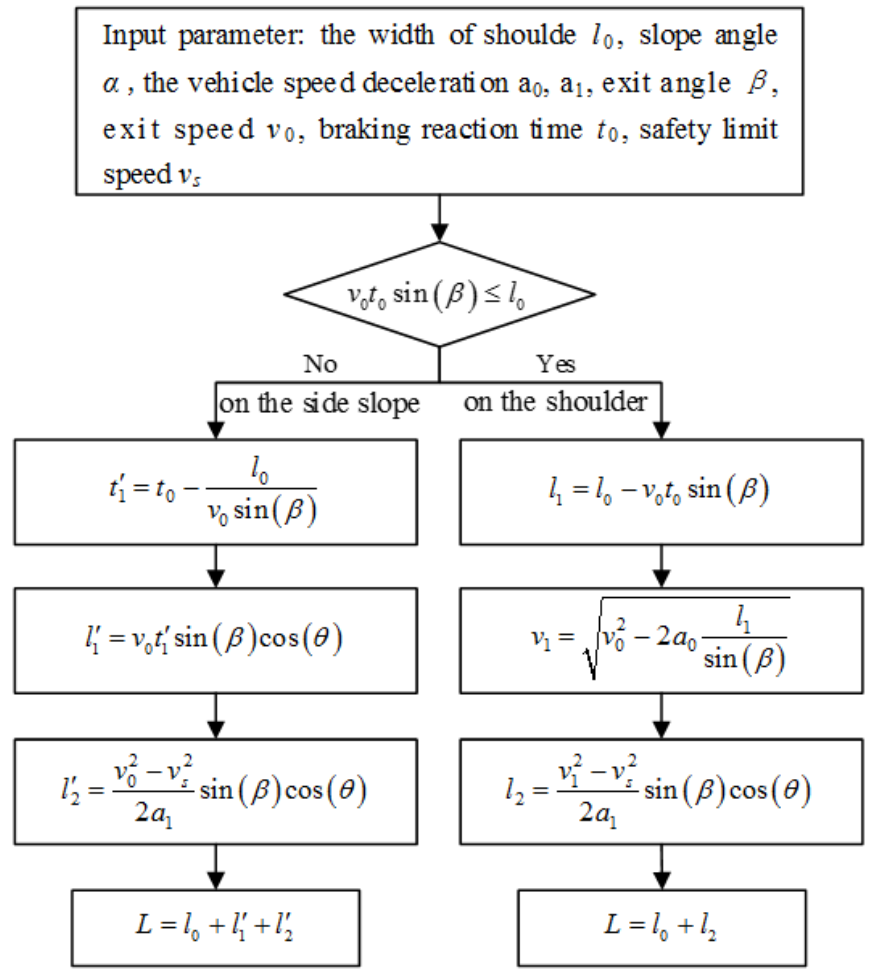

Figure 8. The flow chart of calculation method of clear zone widths

In order to verify the accuracy of the calculation method of roadside width proposed in this paper, as well as the consideration of the high risk of real car test, this paper uses the PC-Crash simulation software to carry out simulation analysis.

Table 2. Theoretical clear zone widths (m)

\begin{tabular}{ccccccccc}
\hline $\begin{array}{c}\text { Departure } \\
\text { angle }\end{array}$ & 50 & 60 & 70 & 80 & 90 & 100 & 110 & 120 \\
\cline { 2 - 9 } $5^{\circ}$ & $1.41 \sim 2.01$ & $2.12 \sim 2.97$ & $2.92 \sim 4.29$ & $4.06 \sim 6.78$ & $5.39 \sim 7.25$ & $6.85 \sim 8.84$ & $8.43 \sim 10.57$ & $10.15 \sim 12.42$ \\
$6^{\circ}$ & $1.70 \sim 2.42$ & $2.54 \sim 3.75$ & $3.63 \sim 5.28$ & $5.06 \sim 6.93$ & $6.66 \sim 8.69$ & $8.40 \sim 10.60$ & $10.31 \sim 12.67$ & $12.37 \sim 14.90$ \\
$7^{\circ}$ & $1.97 \sim 2.87$ & $2.96 \sim 4.48$ & $4.39 \sim 6.21$ & $6.06 \sim 8.08$ & $7.92 \sim 10.13$ & $9.96 \sim 12.36$ & $12.18 \sim 14.78$ & $14.58 \sim 17.37$ \\
$8^{\circ}$ & $2.25 \sim 3.55$ & $3.44 \sim 5.17$ & $5.15 \sim 7.09$ & $7.06 \sim 9.23$ & $9.18 \sim 11.57$ & $11.51 \sim 14.12$ & $14.08 \sim 16.88$ & $16.71 \sim 19.84$ \\
$9^{\circ}$ & $2.53 \sim 3.87$ & $3.99 \sim 5.81$ & $5.91 \sim 7.97$ & $8.06 \sim 10.37$ & $10.44 \sim 13.00$ & $13.00 \sim 15.87$ & $14.88 \sim 18.97$ & $18.78 \sim 22.30$ \\
$1^{\circ}$ & $2.81 \sim 4.30$ & $4.54 \sim 6.45$ & $6.67 \sim 8.85$ & $9.05 \sim 11.51$ & $11.65 \sim 14.44$ & $14.48 \sim 17.62$ & $17.54 \sim 21.06$ & $20.85 \sim 24.75$ \\
$1^{\circ}$ & $3.09 \sim 4.59$ & $5.08 \sim 7.08$ & $7.42 \sim 9.72$ & $10.09 \sim 12.65$ & $12.84 \sim 15.07$ & $15.91 \sim 19.36$ & $19.26 \sim 23.14$ & $22.91 \sim 27.20$ \\
$12^{\circ}$ & $3.39 \sim 5.15$ & $5.62 \sim 7.72$ & $8.17 \sim 10.5$ & $10.96 \sim 13.79$ & $13.99 \sim 16.42$ & $17.34 \sim 21.09$ & $20.99 \sim 25.21$ & $24.96 \sim 29.64$ \\
$13^{\circ}$ & $3.74 \sim 5.57$ & $6.17 \sim 8.35$ & $8.84 \sim 11.5$ & $11.85 \sim 14.92$ & $15.14 \sim 17.76$ & $18.76 \sim 22.82$ & $22.71 \sim 27.28$ & $27.01 \sim 32.07$ \\
$14^{\circ}$ & $4.10 \sim 5.99$ & $6.70 \sim 8.98$ & $9.57 \sim 12.3$ & $12.75 \sim 16.04$ & $16.28 \sim 19.10$ & $20.18 \sim 24.54$ & $24.43 \sim 29.34$ & $29.04 \sim 34.49$ \\
$15^{\circ}$ & $4.45 \sim 6.41$ & $7.23 \sim 9.61$ & $10.2 \sim 13.1$ & $13.64 \sim 17.16$ & $17.42 \sim 21.52$ & $21.58 \sim 26.26$ & $26.14 \sim 31.38$ & $31.07 \sim 36.90$ \\
\hline
\end{tabular}

\section{VERIFICATION OF STIMULATED TESTS}

PC-Crash software is one of the widely used simulation and analysis software for traffic accident simulation. It has many advantages, such as rich model database, automobile dynamics and kinematics simulation ability [11]. Using the model database of PC-Crash software, the standard vehicle model and road model are transferred to the vehicle initial position, initial speed, motion sequence and running track. The running state and parking position of the off-road vehicles can be obtained [12], and the theoretical width clear zone is verified to be consistent with the simulation results.
According to the provisions of the representative vehicle model used in the highway speed estimation in the "JTG B052015 Safety Evaluation Standards", the wheelbase of small vehicles is $\leq 3.5 \mathrm{~m}$, and the wheelbase of large vehicles is $>3.5 \mathrm{~m}$. This article selects BMW 320 as the vehicle's typical model, and the Ford-Carge 1418 as a representative model of a large truck to carry out simulation test conditions. As listed in Table 3, other parameters such as driver response time, road adhesion coefficient, vehicle braking deceleration, and slope gradient. The determination parameters in the theoretical method remain same. Each set of tests is repeated 5 times. The simulation scenario is shown in Figure 9. 
Table 3. Simulation test parameters

\begin{tabular}{cccc}
\hline $\begin{array}{c}\text { Test } \\
\text { number }\end{array}$ & $\begin{array}{c}\text { Running } \\
\text { speed }(\mathbf{k m} / \mathbf{h})\end{array}$ & $\begin{array}{c}\text { Representative } \\
\text { vehicle }\end{array}$ & $\begin{array}{c}\text { Departure } \\
\text { angle }\end{array}$ \\
\hline 1 & 60 & Ford-Carge 1418 & $10^{\circ}$ \\
2 & 70 & Ford-Carge 1418 & $9^{\circ}$ \\
3 & 80 & Ford-Carge 1418 & $8^{\circ}$ \\
4 & 90 & BMW320 & $7^{\circ}$ \\
5 & 100 & BMW320 & $6^{\circ}$ \\
6 & 110 & BMW320 & $5^{\circ}$ \\
7 & 120 & BMW320 & $5^{\circ}$ \\
\hline
\end{tabular}

Table 4. Test results and theoretical results (m)

\begin{tabular}{ccccc}
\hline \multirow{2}{*}{$\begin{array}{c}\text { Test } \\
\text { number }\end{array}$} & \multicolumn{2}{c}{ Test result } & \multicolumn{2}{c}{$\begin{array}{c}\text { Theoretical calculation } \\
\text { results }\end{array}$} \\
& $\begin{array}{c}\text { Braking } \\
\text { distance }\end{array}$ & $\begin{array}{c}\text { The width of } \\
\text { clear zone }\end{array}$ & $\begin{array}{c}\text { Braking } \\
\text { distance }\end{array}$ & $\begin{array}{c}\text { The width of } \\
\text { clear zone }\end{array}$ \\
\cline { 2 - 5 } 1 & 52.08 & 6.77 & 48.48 & 6.34 \\
2 & 63.30 & 7.82 & 61.77 & 7.80 \\
3 & 77.50 & 9.05 & 76.56 & 9.23 \\
4 & 97.78 & 10.60 & 98.83 & 10.13 \\
5 & 121.06 & 11.29 & 110.59 & 10.60 \\
6 & 137.20 & 10.72 & 129.84 & 10.57 \\
7 & 156.11 & 13.25 & 150.58 & 12.42 \\
\hline
\end{tabular}

Through the roadside accident simulation, the test results such as whether rollover occurs and the braking distance after the vehicle has entered the roadside can be obtained. The test results are analyzed as follows:

(1) The vertical force of the wheel is analyzed to determine whether there are serious accidents such as rollover or falling after running. The force of test wheels NO.3 and NO.7 are shown in Figure 10. When the vehicle is rollover, the inner side wheel (left front wheel LV, left rear wheel LH) has a vertical force of 0 . From the test, it is found that the rollover accident on the slope with a ratio of 1:6 will not occur with the speed of $120 \mathrm{~km} / \mathrm{h}$ and below. Therefore, it is proved that the width of the slope can be used as a safe area when the slope ratio is less than 1:6.

(2) The accuracy of the theoretical calculation method is verified by analyzing the braking distance of the vehicle driving into the side of the road. The relationship between the road distance and velocity of each test vehicle is shown in Figure 11, and the results of simulation and the theoretical calculation are listed in Table 4. From the table, it is known that the width of the roadside net area obtained from the simulation experiment is basically the same as that of the theoretical calculation, thus verifying the accuracy of the theoretical calculation method.

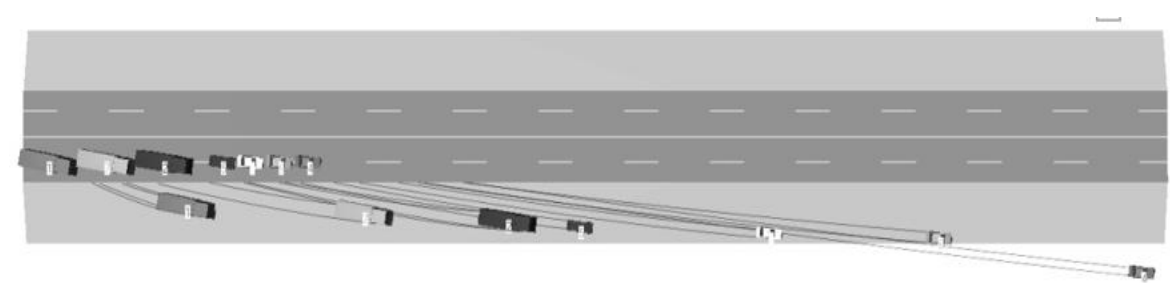

Figure 9. Simulation test of roadside accident

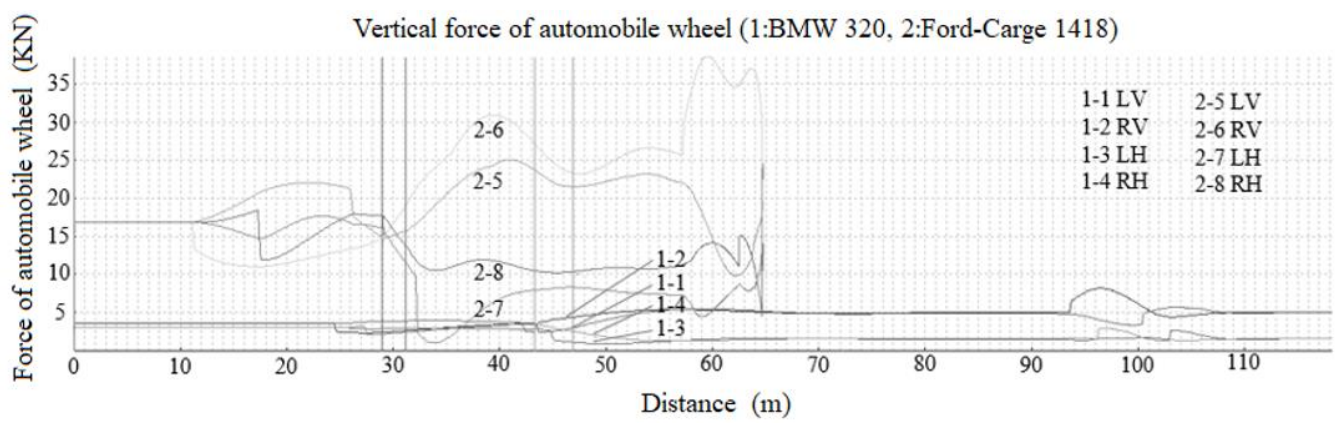

Figure 10. Vertical force of automobile wheel

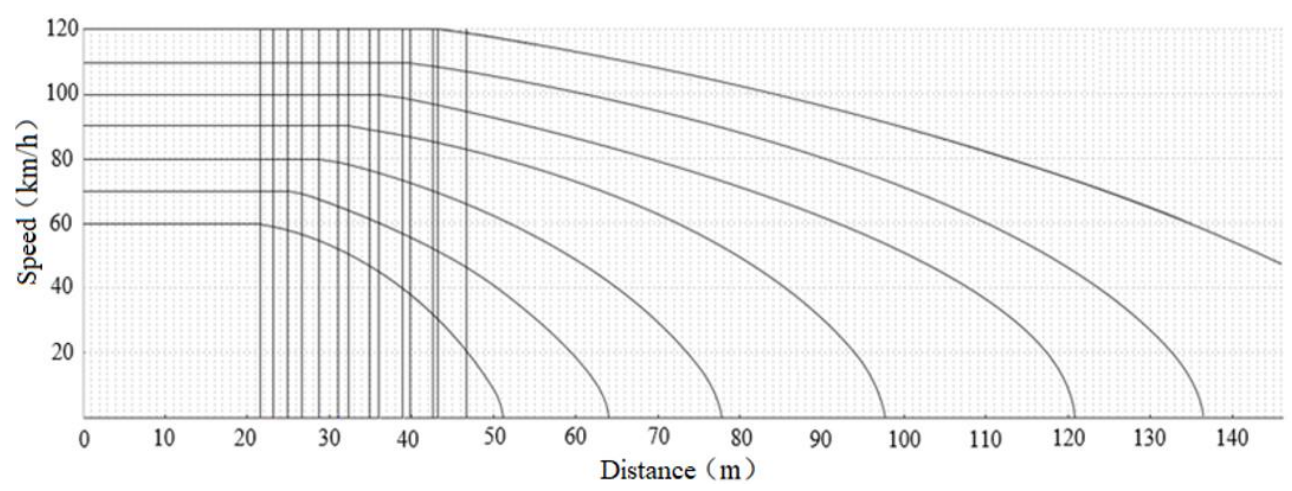

Figure 11. Car distance-speed (driver reaction time $1.3 \mathrm{~s}$ ) 


\section{SUGGESTION VALUES OF CLEAR ZONE WIDTH}

When the standard of the roadside clear zone is determined, the departure speed of the vehicle should not be the standard of the design speed, and in general, the vehicle out of the road is running in the lateral lane [13]. Therefore, this paper selects the average running speed of the most lateral lane as the speed of the vehicle leaving the lane, and obtains the recommended value of the width of the clear zone as listed in Table 5. In addition, as for the flat curve road section, the width of clear zone expands properly, when accidents occur like rushing out of the road to the direction of flat curve tangent line. In this paper, the guide of highway project safety assessment (JTG B05-2015) [4] is used to adjust the width of the lateral side of the flat curve according to the radius, and the correction coefficient is shown in Figure 12.

Seen from Table 5, the need for clear zone width will increase as the average speed goes up, and in some other conditions like land-restriction or mountain cliff area, there should be highly sufficient protection to ensure road safety, if it is unable to fulfill the clear zone of roadside.

Table 5. Recommended width of clear zone

\begin{tabular}{cc}
\hline $\begin{array}{c}\text { Running speed of } \\
\text { the most lateral Lane }(\mathbf{k m} / \mathbf{h})\end{array}$ & $\begin{array}{c}\text { Recommended value of } \\
\text { the width of clear zone }(\mathbf{m})\end{array}$ \\
\hline 50 & $3.0 \sim 4.5$ \\
60 & $4.5 \sim 6.5$ \\
70 & $5.5 \sim 7.5$ \\
80 & $7.0 \sim 9.0$ \\
90 & $8.0 \sim 10.0$ \\
100 & $8.5 \sim 10.5$ \\
110 & $9.0 \sim 11.0$ \\
120 & $10.0 \sim 12.0$ \\
\hline
\end{tabular}

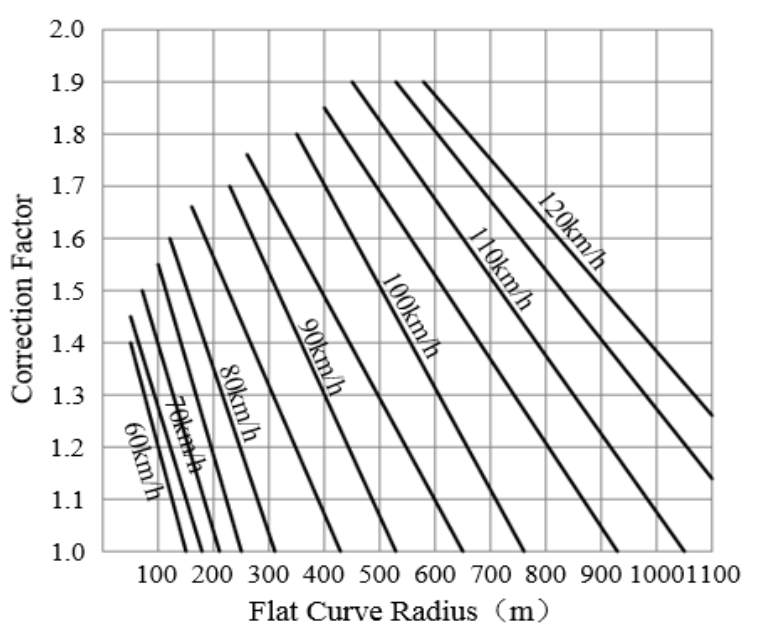

Figure 12. Correction factor of flat curved section

\section{CONCLUSION}

After considering the comprehensive factors of width of clear zone, this paper gives a classically physical calculation method of width of clear zone and also proposing a suggestive constant. Under the simulation, the calculation method will be considered rational and the research results can provide theoretical support for the revision of relevant highway engineering design standards and specifications and highway project safety evaluation guidelines.
In addition, the proposed value of the clear width of the roadside mainly considers the distance of vehicles decelerating to the safety limit speed in the clear zone of the roadside, and does not consider the actual traffic conditions of the road, such as the average daily traffic volume, vehicle composition, traffic density, etc. Therefore, these factors should also be considered when setting the roadside clear zone, for example, in the section with small average daily traffic volume, the requirements for the roadside clear width can be appropriately reduced, and the reasonable recommended roadside clear zone width should be selected based on the actual roadside terrain conditions. Meanwhile, the road designer can take measures such as hardening the shoulder, slowing down the slope rate, setting up passable drainage facilities, removing roadside obstacles and so on to provide sufficient and smooth roadside clear zone as much as possible.

\section{ACKNOWLEDGEMENT}

This research was sponsored by the MOE Layout Foundation of H00Foundation of China (51778063) and China Postdoctoral Science Foundation (2015M581412).

\section{REFERENCES}

[1] American Association of State Highway and Transportation Officials Roadside Design Guide 4th Edition. Washington DC and USA, 2011.

[2] Road Design Manual, Montana Dept. of Transportation: Montana, 2011.

[3] Hakkert, A.S., Gitelman, V. (2014). Thinking about the history of road safety research: Past achievements and future challenges. Transportation Research Part F: Traffic Psychology and Behaviour, 25: 137-149. https://doi.org/10.1016/j.trf.2014.02.005

[4] Ministry of Transport. (2015). Guidelines for Safety Audit of Highway (JTG B05-2015). China Communications Press: Beijing.

[5] Hradil, P., Kala, J., Salajka, V. (2015). Analysis of roadside safety barrier using numerical model. Proceedings of the European Safety and Reliability Conference: Methodology and Applications, pp. 29-32.

[6] Stine, J.S., Hamblin, B.C., Brennan, S.N. (2010). Analyzing the influence of median cross-section design on highway safety using vehicle dynamics simulations. Accident Analysis \& Prevention, 42(6): 1769-1777. https://doi.org/10.1016/j.aap.2010.04.018

[7] Li, L., Zhu, X.C., Ma, Z.X. (2014). Driver brake reaction time under real traffic risk scenarios. Automotive Engineering, 36(10): 1224-1229.

[8] Jurecki, R.S., Stańczyk, T.L., Jaśkiewicz, M.J. (2017). Driver's reaction time in a simulated, complex road incident. $\quad$ Transport, $32(1)$ : 44-54. https://doi.org/10.3846/16484142.2014.913535

[9] Mitschke, M., Wallentowitz, H. (2009). Dynamics of Motor Vehicles. Tsinghua University Press: Beijing.

[10] Xing, Y.Y., Lu, L.J., Lu, J.J., Zhu, S.X. (2013). A study on the widths design of highway roadside clear zone by considering multi-factors. Procedia -Social and Behavioral Sciences, 96: 2584-2594. https://doi.org/10.1016/j.sbspro.2013.08.289

[11] Martínez, F., Páez, J., Furones, A. (2016). Pedestrian- 
vehicle accidents reconstruction with PC-Crash ${ }^{\circledR}$ : sensibility analysis of factors variation. Transportation Research Procedia, 18: $115-121$. https://doi.org/10.1016/j.trpro.2016.12.016

[12] Brach, R.M., Brach, R.M., Mink, R.A. (2015). Nonlinear optimization in vehicular crash reconstruction. SAE International Journal of Transportation Safety, 3(1): 1727. https://doi.org/10.4271/2015-01-1433
[13] Fitzpatrick, C.D., Samuel, S., Knodler Jr., M.A. (2016). Evaluating the effect of vegetation and clear zone width on driver behavior using a driving simulator. Transportation Research Part F: Traffic Psychology and Behavior, 42(1): 80-89. 